\title{
Contemporaneidades do Ensino de Anatomia Humana
}

\author{
Michele Schultz* \\ Escola de Artes, Ciências e Humanidades da Universidade de São Paulo \\ * Autora para correspondência: mschultz@usp.br
}

\section{RESUMO}

As estratégias de ensino devem respeitar a formação profissional e acompanhar a dinâmica sociocultural. A forma de passar e adquirir conhecimento mudou ao longo dos séculos, mas a disciplina de Anatomia Humana pauta-se pelo tradicionalismo e aplica métodos muito semelhantes aos adotados no século XIII, quando ela foi criada. Neste relato, questiona-se a efetividade do ensino tradicional de Anatomia Humana, baseado na memorização, e se apresentam estratégias alternativas utilizadas em cursos de graduação da Escola de Artes, Ciências e Humanidades da Universidade de São Paulo. Tais estratégias estão baseadas em preceitos que conduzam a/o estudante à condição de protagonista de seu aprendizado, construído a partir de suas experiências e futuras competências profissionais.

Palavras-chave: Anatomia Humana; Ensino; Aprendizagem; Metodologias Ativas.

\begin{abstract}
The teaching strategies must respect the professional formation following the social-cultural dynamics. The ways to pass and to acquire knowledge have changed through the centuries, but the discipline of Human Anatomy has been regulated by traditionalism and applies methods very similar to that adopted in the 13th century, when the discipline was created. This report puts in question the effectiveness of the traditional teaching of Human Anatomy, based on memorization, and presents alternative strategies applied to undergraduate courses of the School of Arts, Sciences and Humanities of the University of São Paulo. Such strategies are based on principles that lead the student to the status of protagonist of her/his learning, constructed as from her/his experiences and future professional skills.
\end{abstract}

Keywords: Human Anatomy; Teaching; Learning; Active Methodologies.

\section{Introdução}

A sociedade contemporânea clama por mudanças comportamentais, atitudinais e de relacionamento. Para que tais mudanças se estabeleçam, é necessária uma revisão de paradigmas que, reiteradas vezes, ferem valores que pautam a participação cidadã em prol do coletivo. As/os profissionais que pretendemos formar devem acompanhar os movimentos da sociedade, entendendo as necessidades prioritárias dentro de cada área de atuação. Para que as/os estudantes de graduação acompanhem esse movimento, os currículos dos cursos não deveriam cumprir regras previamente estabelecidas que não considerem os constantes processos de mudança. Em outras palavras, os projetos político-pedagógicos dos cursos de graduação devem ser constantemente revistos a partir de um processo de construção que conte com a participação de todas/os as/os envolvidas/os. Um dos elementos que deve fazer parte da revisão é o método pedagógico aplicado às diferentes disciplinas. A forma de ensinar e aprender deveria acompanhar o dinamismo sociocultural, especialmente ao considerarmos a sociedade da informação ou, pelo menos, a de acesso à informação.

Desde o século XIII, quando a disciplina de Anatomia Humana foi criada pelo catedrático Mondino de Luzzi, as estratégias de ensino utilizadas são praticamente as mesmas. O retrato de um professor em um estandarte, assistido por técnicos responsáveis pela dissecção, ensinando alunos ao 
redor de cadáveres, de certa forma, não mudou ao longo do tempo. No entanto, os conceitos de como ensinar e aprender mudaram muito, especialmente no século passado.

Algumas questões emergem do cenário colocado anteriormente:

- Como aplicar conceitos pedagógicos que façam com que a Anatomia Humana possa ser ensinada de forma contemporânea?

- É preciso modificar as estratégias didáticas?

- Há necessidade de mudanças na formação docente?

De fato, o ensino sofreu mudanças que acompanharam avanços da sociedade do conhecimento. Nos séculos XVIII, XIX e parte do século XX, o ensino visava à produção de mão de obra, acompanhado pelo pensamento mecanicista aplicado ao conhecimento. Tal pensamento, que contribuiu para a (r)evolução industrial, alterou a forma de pensar da sociedade contemporânea e pode ser considerado como o pivô da consolidação do capitalismo e da produção em massa. Após a revolução tecnológica, a forma de transmitir informação e conhecimento mudou radicalmente. Se antes era necessária a figura de uma/um mentora/tor, tida/o como a/o detentora/tor do conhecimento, agora as/ os estudantes fazem parte do processo de construção do seu aprendizado.

O pensamento mecanicista pode ser incentivado em uma sala de aula ou laboratório de Anatomia, especialmente quando o corpo, objeto de estudo e trabalho, é apartado de qualquer senso de humanidade ou pessoalidade, aspectos que podem comprometer a formação de profissionais de saúde. A atuação de tais profissionais prevê um cuidado humanitário, holístico, que considera a pessoa para além das condições físicas e patológicas que a afligem e/ou a adoecem, com culturas e dinâmicas próprias, fatores importantes quando se trata de Saúde e seu significado mais amplo.

Em tal contexto, o objetivo deste relato é apresentar a experiência de ensinar Anatomia Humana considerando dois tópicos de intervenção:

- o ensino através de uma abordagem interdisciplinar;
- o ensino através do uso de estratégias com foco nas experiências e nos corpos das/os próprias/os estudantes, sem utilização de peças cadavéricas.

\section{Anatomia e Fundamentos Biológicos}

Estratégias que colocam a/o estudante em uma condição de passividade carecem de efetividade, que deve ser medida não somente pelo conhecimento específico, mas também por uma série de competências que caracterizam uma formação global, generalista, condizente com a realidade da sociedade na qual a/o estudante e futura/o profissional está inserida/o. Assim, os paradigmas que norteiam o ensino contemporâneo devem considerar o cenário político, social e cultural.

Diante do exposto e entendendo que a/o estudante deve protagonizar seu aprendizado, sendo este dotado de significado e pautado em experiências prévias, criou-se na Escola de Artes, Ciências eHumanidades (EACH) da Universidade de São Paulo um conjunto de disciplinas denominadas Fundamentos Biológicos, que são oferecidas para os cursos de Educação Física e Saúde, Gerontologia e Obstetrícia. O conteúdo das disciplinas e sua sequência temática foram desenhados para que haja a integração de saberes das áreas de Morfologia, Fisiologia, Bioquímica, Biologia Celular e Farmacologia em torno de um sistema corporal.

Dentre os pilares da fundação da EACH, está a inovação pedagógica, que coloca a/o estudante em uma situação de protagonismo, sendo responsável pelo seu aprendizado. Para que isso aconteça, as estratégias utilizadas não devem ser as convencionais, tradicionalmente aplicadas e replicadas, imitando modelos jesuíticos e napoleônicos de ensino. As estratégias devem ser revistas e renovadas, induzindo a/o estudante à criticidade, à reflexão e à criatividade, habilidades que, certamente, serão diferenciais na sua formação profissional.

Nas disciplinas de Fundamentos Biológicos, o ensino e o aprendizado de Anatomia dos Sistemas Corporais são conferidos através de estratégias que valorizam a compreensão da forma pela função, com foco na atuação profissional. São utilizadas diversas 
estratégias que, geralmente, emergem de situações do cotidiano da/o estudante ou que tenham relação com sua futura atuação profissional. Considerando que o conhecimento depende da relação entre a motivação das/os estudantes e o aprendizado, situações vivenciadas por elas/es fazem com que a temática tenha significação e, portanto, o interesse em entender um fenômeno ou acontecimento amplia a possiblidade de aprendizado concreto. As estratégias didáticas incluem aulas expositivo-dialogadas, discussões em grupo, seminários, mostras, oficinas de construção, resolução de problemas e estudos de casos, visando a integrar os conteúdos da disciplina com a prática profissional (Figura 1). O trabalho em grupo é utilizado em quase todas as aulas para que, além de a/o aluna/o participar da construção do seu conhecimento, competências como afetividade, divisão e organização do trabalho, resolução de conflitos, avaliação e autoavaliação sejam praticadas. As avaliações também são diversificadas e, quando realizadas individualmente na sala de aula, são feitas com consulta a anotações e livros.
Dentre os métodos de ensino mais antigos e tradicionais aplicados aos cursos da área da Saúde está o utilizado na Anatomia Humana. Classicamente, utilizam-se peças cadavéricas, e a memorização de estruturas é o foco do estudo. Apresentam-se listas de estruturas para serem memorizadas, geralmente desconsiderando o eixo profissionalizante do curso ou conhecimentos prévios da/o estudante. Essa descontextualização diminui o interesse da/o estudante, o que dificulta o aprendizado. O pressuposto de um método pautado na memorização, que se aproxima do mesmo adotado pelo modelo jesuítico, é o da formação tecnicista, em que a criatividade e a reflexão não são incentivadas e praticadas. Vários estudos apontam para a necessidade de revisão desse método de ensino em cursos de Medicina (McLACHLAN et al., 2004; McLACHLAN \& PATTEN, 2006; TURNEY, 2007), já que sua aparente efetividade pode suplantar outros conhecimentos essenciais para a prática profissional, tais como as artes e as humanidades (McLACHLAN \& PATTEN, op. cit.).

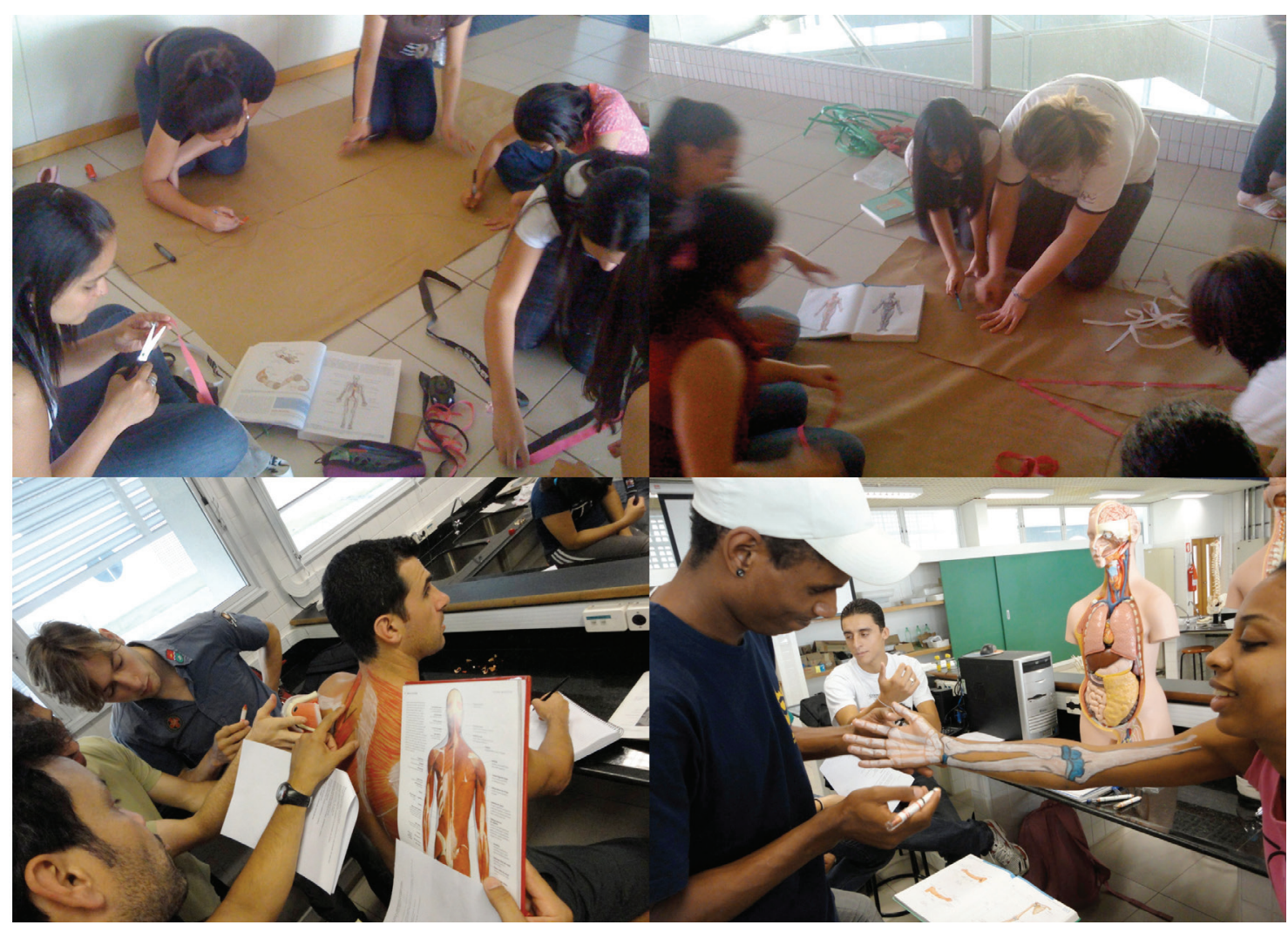

Figura 1 - Fotos ilustrando estratégias utilizadas para ensino de Anatomia Humana nas disciplinas de Fundamentos Biológicos na EACH-USP. Os alunos realizam atividades em grupo como oficinas de construção para representação do sistema cardiocirculatório (fotos superiores) ou pintura corporal para representação de estruturas do sistema locomotor (fotos inferiores). 


\section{Considerações Finais}

A ausência de cadáveres como ferramenta de ensino de Anatomia Humana fez com que eu buscasse alternativas de ensino que hoje considero suficientes para o ensino e aprendizado dessa disciplina. Embora a utilização de cadáveres seja extremamente importante para a formação em algumas áreas médicas, não é necessária para todos os estudantes de cursos da Saúde. A forma com que a disciplina é apresentada e praticada pode contribuir para a formação desumanizada e fragmentada. As especialidades médicas, muitas vezes, reduzem as condições de saúde ou doença a um fragmento do corpo, ignorando outros sistemas e suas relações. A compartimentalização do corpo, prática iniciada no laboratório de Anatomia, pode se estender aos consultórios e atendimentos.

Pelo exposto, questiono a forma com que se utilizam cadáveres para ensino de Anatomia Humana a vários cursos da área de Saúde. Se estabelecermos relações entre o método aplicado e as habilidades e competências profissionais almejadas nos projetos políticos pedagógicos, talvez concluamos que podemos atualizar a forma de ensinar Anatomia. Métodos híbridos, em que o foco não seja o cadáver ou a memorização, podem melhor representar a contemporaneidade que a Anatomia Humana merece e necessita.

\section{Bibliografia}

ANASTASIOU, Léa das Graças Camargo. "Da Visão de Ciência à Organização Curricular". In: \& ALVES, Leonir Pessate (orgs.). Processos de Ensinagem na Universidade: Pressupostos para as Estratégias de Trabalho em Aula. Joinvile: Editora Univille, 2006, pp. 35-60.

FREIRE, Paulo. Pedagogia da Autonomia: Saberes Necessários à Prática Educativa. São Paulo: Paz e Terra, 1996.

McLACHLAN, John C.; BLIGH, J.; BRADLEY, P. \& SEARLE, J. "Teaching Anatomy without Cadavers". Medical Education, vol. 38, n. 4, 2004, pp. 418-424.

\& PATTEN, D. "Anatomy Teaching: Ghosts of the Past, Present and Future". Medical Education, vol. 40, n. 3, 2006, pp. 243-253.

TURNEY, Ben W. "Anatomy in a Modern Medical Curriculum". Annals of The Royal College of Surgeons of England, vol. 89, n. 2, 2007, pp. 104-107.

VYGOTSKY, Lev Semenovich. A Formação Social da Mente. São Paulo: Martins Fontes, 1998.

Publicado em 31/03/2017. 